Gut, 1960, 1, 44.

\title{
SEROTONIN, BANANAS, AND DIARRHOEA .
}

\author{
BY
}

A. M. CONNELL, ${ }^{*}$ E. N. ROWLANDS, and P. B. WILCOX*

From the Department of Gastroenterology, Central Middlesex Hospital, London, and M.R.C. Clinical Research Unit, University College Hospital, London

From previous studies on serotonin it seemed possible that it might play a major rôle in determining the rhythm of the bowel in man. This hypothesis was tested, with negative results, by observing the effect of giving bananas, a rich natural source of serotonin, to normal subjects and by measuring the excretion of 5-hydroxyindolacetic acid in patients with diarrhoea.

"Is 5-hydroxytryptamine (5-H.T.) Nature's ramedy for constipation?" This speculation (Collier, 1958) about a possible rôle for 5-H.T. was prompted by the following observations: it is present in the intestinal mucosa in higher concentration than in any other tissue of the body; it causes isolated pieces of intestine to contract; and when given to mice by injection (Erspamer, 1952) or by mouth it increases the amount of faeces passed, "as a much larger dose of senna does" (Collier, 1958). Bülbring and Lin (1958) have also recently shown that 5-H.T. stimulates peristalsis when introduced into the lumen of the isolated guinea-pig intestine. These observations lend some support to the view that 5-H.T. may be concerned in the regulation of bowel function in some animals, and, by inference, in man, especially as diarrhoea is a prominent symptom of the carcinoid syndrome. We have, therefore, tried to obtain further evidence about the relationship between 5-H.T. and bowel function in man in two separate studies.

As very little is known about the fate of 5-H.T. or its effect on intestinal motility when given by mouth, we observed the effects of feeding large amounts of it in the form of bananas to a group of normal subjects and measured its excretion in the urine as 5-hydroxyindoleacetic acid (5-H.I.A.A.). Anderson, Ziegler, and Doeden (1958) noted that monkeys excreted much more 5-H.I.A.A. when bananas were added to their diet, and Waalkes, Sjoerdsma, Creveling, Weissbach, and Udenfriend (1958) showed that this was because bananas contain large amounts of serotonin. This surprising finding was of further interest because bananas have enjoyed a traditional reputation in the treatment of coeliac disease and other bowel disorders. In our second

*In receipt of grants from the Medical Research Council. study we measured the excretion of 5-H.I.A.A. in patients suffering from chronic diarrhoea and steatorrhoea, since it seemed possible that overproduction of 5-H.T. might be concerned in the aetiology of this obscure group of diseases.

\section{MeTHOD}

Specimens of urine were collected over 24-hour periods, and the 5-H.I.A.A. was estimated by the method of Macfarlane, Dalgliesh, Dutton, Lennox, Nyhus, and Smith (1956) which is a modification of the method of Udenfriend, Titus, and Weissbach (1955). Chromatography was not performed as it has been shown that the colour reaction is produced mainly by 5-H.I.A.A. The recovery of known amounts of 5-H.I.A.A. added to urine averaged $88 \%$ over a range of concentration of 8 to $20 \mu \mathrm{g} . / \mathrm{ml}$.

\section{RESULtS}

The daily excretion of 5-H.I.A.A. in 19 normal subjects ranged from 1.9 to $7.6 \mathrm{mg}$. with a mean of $3.9 \mathrm{mg}$. The individual values are shown in Fig. 1 . Unlike a number of physiological substances, there does not appear to be any diurnal variation in the excretion of 5-H.I.A.A. (Table I). Our results are rather lower than those of Macfarlane et al. (1956) (range 3.2 to $13.7 \mathrm{mg}$. per day) but correspond closely to the normal values quoted by Udenfriend and other authors. In two patients with carcinoid tumours, subsequently confirmed at necropsy, the mean excretion of 5-H.I.A.A. was $51 \mathrm{mg}$. and $81 \mathrm{mg}$. per 24 hours respectively.

EFFECTS of EATING BanANas.-Six normal subjects collected urine for 24 hours in three separate eight-hourly periods. On the following day the same procedure was observed but during the first three hours each subject ate 12 bananas, most of which were eaten in the first hour. A marked and 


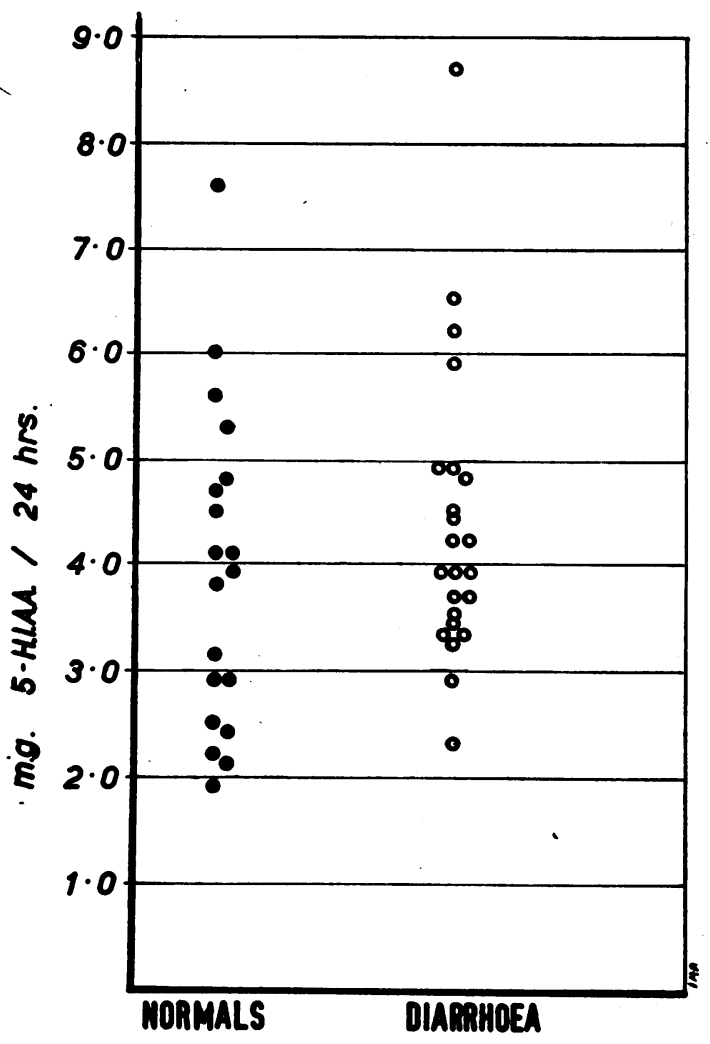

Fig. 1.-Daily excretion of 5-H.I.A.A. in 19 normal subjects.

rapid rise in 5-H.I.A.A. excretion was observed on the day the bananas were eaten (Table I), the mean increase being $22 \cdot 3 \mathrm{mg}$. Waalkes et al. (1958) found that the serotonin content of banana pulp ranged from 8 to $50 \mu \mathrm{g} . / \mathrm{g}$. and averaged $28 \mu \mathrm{g} . / \mathrm{g}$., the average weight of pulp per banana being $130 \mathrm{~g}$. Although our bananas were large by British standards, the pulp weighed only about $100 \mathrm{~g}$., and their serotonin content was also probably lower than that of the American bananas since West (1958), working in London, obtained values of 19.0 to $25.0 \mu \mathrm{g}$. of
5-H.T. per g. of pulp. Assuming that the amount of serotonin in each banana was between 1.9 and $2.5 \mathrm{mg}$., each of our subjects ingested between 23 and $30 \mathrm{mg}$. of 5-H.T., and excreted between $75 \%$ and $100 \%$ of it as 5-H.I.A.A. in 24 hours (the ratio of the molecular weights of 5-H.T. and 5-H.I.A.A. is 0.92 ).

The rate of elimination from the body was rapid, the greater proportion being excreted in the first eight hours, when the level of urinary 5-H.I.A.A. was well into the range found in patients with carcinoid tumours. The mean rate of excretion in the first eight-hour period after ingestion of bananas was $2.3 \mathrm{mg}$. per hour, compared with $2.1 \mathrm{mg}$. and $3.4 \mathrm{mg}$. per hour respectively in our two patients with carcinoid tumours.

The ingestion of as few as three bananas was sufficient to raise the excretion of 5-H.I.A.A. above the normal limit in our subjects, the excretion in the first eight hours averaging $4.9 \mathrm{mg}$. more than in the corresponding control period.

None of the subjects developed symptoms which could not be attributed to increased bulk alone, even though four of them ate 12 bananas daily for six days in addition to their normal diet, their excretion of 5-H.I.A.A. averaging $28.7 \mathrm{mg}$. on the first day and $34.0 \mathrm{mg}$. on the sixth. Most of them experienced a sensation of satiety from overeating, but none of them complained of diarrhoea, urgency, colic, or borborygmi.

Urinary 5-H.I.A.A. IN Chronic Diarrhoea.The excretion of 5-H.I.A.A. was measured in 20 patients suffering from chronic diarrhoea of unknown aetiology and without steatorrhoea. Eleven of these complained of persistent early morning diarrhoea, and the remaining nine patients had frequent attacks of profuse diarrhoea alternating with periods of complete or partial remission. Two patients with ulcerative colitis and one with Crohn's disease were also studied. The mean excretion of 5-H.I.A.A. in this group of patients was $4.3 \mathrm{mg}$. per day, and Fig. 1 shows that the scatter of the individual values is essentially the same as in normal subjects.

TABLE I

EFFECT OF EATING 12 BANANAS ON URINARY EXCRETION OF 5-H.I.A.A. (MG.)

\begin{tabular}{|c|c|c|c|c|c|c|c|c|}
\hline \multirow[b]{2}{*}{ Subject } & \multicolumn{4}{|c|}{ Control Day } & \multicolumn{4}{|c|}{ Experimental Day } \\
\hline & 3-11 p.m. & 11 p.m.-7 a.m. & 7 a.m.-3 p.m. & Total & 3-11 p.m. & 11 p.m.-7 a.m. & 7 a.m.-3 p.m. & Total \\
\hline $\begin{array}{l}\text { M.F. } \\
\text { E.C. } \\
\text { E.N.R. } \\
\text { A.M.C. } \\
\text { P.B.W. } \\
\text { A.C. }\end{array}$ & $\begin{array}{l}2.0 \\
1.3 \\
1.4 \\
0.8 \\
0.9 \\
1.4\end{array}$ & $\begin{array}{l}2.1 \\
1.3 \\
1.4 \\
0.8 \\
1.0 \\
0.6\end{array}$ & $\begin{array}{l}1.2 \\
1.5 \\
1.1 \\
0.8 \\
1.0 \\
2.8\end{array}$ & $\begin{array}{l}5 \cdot 3 \\
4 \cdot 1 \\
3.9 \\
.2 \cdot 4 \\
2.9 \\
4.8\end{array}$ & $\begin{array}{r}22.4 \\
8.4 \\
19.8 \\
16.5 \\
25.9 \\
19.3\end{array}$ & $\begin{array}{l}7.9 \\
6.5 \\
4.0 \\
3.2 \\
1.9 \\
9.0\end{array}$ & $\begin{array}{l}1.2 \\
5.1 \\
2.0 \\
1.2 \\
0.5 \\
2.4\end{array}$ & $\begin{array}{l}31.5 \\
20 \cdot 0 \\
25 \cdot 8 \\
20.9 \\
28 \cdot 3 \\
30 \cdot 7\end{array}$ \\
\hline Mean & $1 \cdot 3$ & $1 \cdot 2$ & 1.4 & 3.9 & $18 \cdot 7$ & 5.4 & $2 \cdot 1$ & $26 \cdot 2$ \\
\hline
\end{tabular}


UrINARY 5-H.I.A.A. in SteatorRHOEA.-This group consisted of nine patients with idiopathic steatorrhoea (Table II), and eight in whom the

TÁBLE II

URINARY EXCRETION OF 5-H.I.A.A. (MG. per 24 HR.) IN PATIENTS WITH IDIOPATHIC STEATORRHOEA

\begin{tabular}{|c|c|c|c|}
\hline Patient No. & In $\mathbf{R}$ & Relapse & Treated with Gluten-free Die \\
\hline $\begin{array}{l}1 \\
2 \\
3 \\
4 \\
5 \\
6 \\
7 \\
8 \\
9\end{array}$ & $\begin{array}{l}3 \cdot 9 \\
4 \cdot 0 \\
4 \cdot 0 \\
6 \cdot 4 \\
7 \cdot 3 \\
9 \cdot 1 \\
3 \cdot 1 \\
2 \cdot 1\end{array}$ & $\begin{array}{ll}2 \cdot 7 & 4 \cdot 0 \\
4 \cdot 7 & \\
& \\
4 \cdot 1 & 8.4 \\
4.8 & \\
- & \\
\end{array}$ & 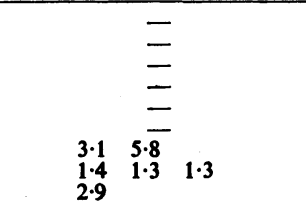 \\
\hline
\end{tabular}

steatorrhoea was secondary to one of the diseases listed in Table III. One of the patients with the Zollinger-Ellison syndrome has been described elsewhere by Summerskill (1959). Both the others had pancreatic tumours. The diagnosis of idiopathic steatorrhoea was made only after intensive investigations had failed to reveal any cause for the condition.

\section{TABLE III}

URINARY EXCRETION OF 5-H.I.A.A. (MG. PER 24 HR.) IN PATIENTS WITH SECONDARY STEATORRHOEA

Zollinger-Ellison Syndrome

1 ....................... 4.1

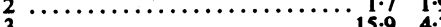

....................15.9 $4 \cdot 3$

Pancreatic Steatorrhoea

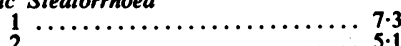

Post-gastrectomy Steatorrhoea

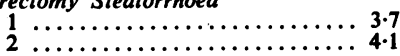

Ileo-colitis $\ldots \ldots \ldots \ldots \ldots \ldots \ldots \ldots \ldots \ldots .7 .4 \quad 3.6 \quad 11 \cdot 1$

In the patients with idiopathic steatorrhoea the urinary excretion of 5-H.I.A.A. ranged from 1.3 to $9.1 \mathrm{mg}$. per day. Table II shows the individual values in six patients in relapse, in one patient who was in a remission induced by a gluten-free diet, and in two patients before and after treatment with gluten-free diets. Normal values were obtained in all these patients, whether in relapse or in remission, except that two out of three estimations in one patient were just outside our normal range though within the commonly accepted range of 2 to $10 \mathrm{mg}$. per day (Pernow, 1958). In the patients with secondary steatorrhoea (Table III) the urinary levels were within the normal range with two exceptions: in one of the patients with the Zollinger-Ellison syndrome, one of the two estimations was well above the normal range; and one out of three estimations in the patient with ileocolitis was slightly elevated.

\section{Discussion}

Variations in diet, including major variations in the tryptophan content, are said to have little or no effect on the urinary 5-H.I.A.A. (Pernow, 1958). The excretion of this substance is regarded as the best index of the total production of 5-H.T. in the body, and is used as a specific test in the diagnosis of carcinoid tumours. It is therefore important to realize that the ingestion of a few bananas will raise the urinary 5-H.I.A.A. above the normal range because of their large content of serotonin. Of this, a high proportion, possibly as much as $100 \%$, is rapidly excreted as 5-H.I.A.A. in normal individuals, and this might prove useful as a test of intestinal absorption. There is no satisfactory method of measuring the absorption of nitrogenous substances (Rowlands, 1959), but the oral administration of known amounts of serotonin and subsequent estimation of urinary 5-H.I.A.A. is a simple procedure which would appear to be worthy of further study in this connexion.

None of the subjects who ate bananas suffered from diarrhoea or any other abdominal symptoms although some of them consumed about $30 \mathrm{mg}$. of serotonin daily for a week, and their urinary 5-H.I.A.A. was elevated into the range commonly regarded as diagnostic of carcinoid tumour. Hendrix, Atkinson, Clifton, and Ingelfinger (1957) found that the instillation of up to $30 \mathrm{mg}$. of 5-H.T. into the lumen of the jejunum had no effect on intestinal motility as recorded by a balloon in normal subjects. These findings in man are in marked contrast to the effect of oral 5-H.T. on the intestine in animals (Collier, 1958), and also to Bülbring and Lin's (1958) observation that peristalsis was stimulated when 5-H.T. was introduced into the lumen of isolated guinea-pig ileum. It may be that species differences are important since Bülbring and Lin noted that the stimulating effect of intraluminal 5-H.T. developed more slowly and was less marked and more transient in rabbit jejunum than in guineapig ileum.

However, it has been shown experimentally in man that the intravenous injection of 5-H.T. usually stimulates intestinal motility (Hendrix et al., 1957), and it is commonly believed that it is the overproduction of 5-H.T. which accounts for the diarrhoea in the carcinoid syndrome. It therefore seemed possible that it might also be a factor in the aetiology of the chronic diarrhoeas, but the production of 5-H.T. in our patients was within normal limits, as judged by their excretion of 5-H.I.A.A. Kowlessar, Williams, Law, and Sleisenger (1958) also found normal values in patients with diarrhoea without steatorrhoea. In patients with "symptomatic nontropical sprue", however, these authors found that 
the urinary excretion was high but it returned to normal levels when the symptoms had been controlled by a gluten-free diet. Although the majority of our patients with idiopathic steatorrhoea were either untreated or in relapse, only one of them showed a raised excretion of 5-H.I.A.A. and this was so small as to be of doubtful significance. There was no change in the urinary 5-H.I.A.A. of two patients who were studied before and after treatment with gluten-free diets. Krikler (1958) also reported a case of idiopathic steatorrhoea in which the excretion of 5-H.I.A.A. was normal. Haverback and Davidson (1958) made repeated measurements on two patients with non-tropical sprue and found that some of the 5-H.I.A.A. values "appeared to be border-line elevations". The 5-H.I.A.A. values were also normal in our patients with secondary steatorrhoea, with the exception of one of the patients with the Zollinger-Ellison syndrome associated with a malignant pancreatic tumour. The significance of the high value obtained in this patient is not apparent.

Although 5-H.T. is probably concerned in the control of intestinal motility, its precise role in normal intestinal physiology is speculative, and we have not found any evidence that it plays an important part in the aetiology of disorders of bowel function in man. Even in the carcinoid syndrome the correlation between 5-H.T. production and the occurrence of diarrhoea is poor; and a significant number of the patients never suffer from diarrhoea throughout their illness, e.g., 15 out of 79 patients with malignant carcinoids reviewed by Thorson (1958). Thus, while it is reasonable to suppose that the overproduction of 5-H.T. may be a cause of the diarrhoea, it seems likely that the mechanical effect of the tumour is also a factor since it is located in the intestine in the majority of the patients.

\section{SUMmary}

The daily ingestion of large amounts of serotonin in bananas did not affect bowel function in man, in contrast to the effect of oral and intraluminal 5-H.T. in animals.

A high percentage of the 5-H.T. content of the bananas was rapidly excreted as 5-H.I.A.A. in the urine; this might prove useful as a test of the intestinal absorption of a nitrogenous substance. The ingestion of three bananas was sufficient to raise the urinary 5-H.I.A.A. above the normal range.

There was no evidence of overproduction of 5-H.T. in patients with chronic diarrhoea of unknown aetiology or in idiopathic steatorrhoea. The excretion of 5-H.I.A.A. was also normal in secondary steatorrhoea, except in one out of three patients with the Zollinger-Ellison syndrome.

We wish to thank Dr. F. Avery Jones and Dr. T. D. Kellock for allowing us to study their patients, and The Upjohn Company for providing us with 5-hydroxyindoleacetic acid.

\section{REFERENCES}

Anderson, J. A., Ziegler, M. R., and Doeden, D. (1958). Science, 127,236

Bülbring, E., and Lin, R. C. Y. (1958). J. Physiol. (Lond.), 140, 381. Collier, H. O. J. (1958). In 5-Hydroxytryptamine, p. 18, ed. G. P. Lewis. Pergamon Press, London.

Erspamer, V. (1952). Ric. Sci. 22, 694.

Haverback, B. J., and Davidson, J. D. (1958). Gastroenterology, 35,570 .

Hendrix, T. R., Atkinson, M., Clifton, J. A., and Ingelfinger, F. J.

(1957). Amer. J. Med., 23, 886. J. A., and Ingelfinger, F. J.
Kowlessar, O. D., Williams, R. C., Law, D. H., and Sleisenger, M. H. (1958). New Engl. J. Med., 259, 340.

Krikler, D. M. (1958). Lancet, 2, 216.

Macfarlane, P. S., Dalgliesh, C. E., Dutton, R. W., Lennox, B. Nyhus, L. M., and Smith, A. N. (1956). Scot. med. J., 1, 148 ow, B. (1958). In Modern Trends in Gastro-enterology (Second Series), ed. F. Avery Jones, p. 101. Butterworth, London.

Rowlands, E. N. (1959). Proc. roy. Soc. Med., 52, 1.

Rowlands, E. N. (1959). Proc. roy. Soc. Med.,

Thorson, A. H. (1958). Acta med. scand., 161, Suppl. 334.

Udenfriend, S., Titus, E., and Weissbach, H. (1955). J. biol Chem. 216, 499 .

Waalkes, T. P., Sjoerdsma, A., Creveling, C. R., Weissbach, H., and West, G. B. (1958). J. Pharm. Pharmacol., 10, 589. 